\title{
Ankündigung der Redaktion Buchsprechungen
}

Mit dieser Ausgabe der Publizistik erfolgt eine Änderung im Layout des Rezensionsteils. Und zwar werden die einzelnen Rezensionen nicht mehr direkt hintereinander gesetzt, sondern jede Rezension beginnt auf einer rechten Zeitschriftenseite. Damit werden die Rezensionen produktionstechnisch wie die Aufsätze als Einzeltexte behandelt, die online wesentlich leichter aufzufinden sein werden. Im Rahmen dieser Umstellung wird es in der Druckausgabe vorübergehend größere Weißraumflächen geben. Dies wird sich jedoch in den folgenden Ausgaben reduzieren, da die Standardlänge der Rezensionen in Zukunft länger sein und in etwa zwei Druckseiten umfassen wird. 